\title{
CRYOGLOBULINEMIC VASCULITIS WITH RENAL INVOLVEMENT IN A YOUNG WOMAN: A CASE OF MONOCLONAL GAMMOPATHY OF RENAL SIGNIFICANCE
}

Heitor Furlan Giordano, ${ }^{1 \star \star}$, Jean Michell Correia Monteiro1', Lissiane Karine Noronha Guedes', Henrique Ayres Mayrink Giardini', Pedro Pereira Neffá1; Dalila Nunes Cysne ${ }^{1}$, Rosa Maria Rodrigues Pereira ${ }^{1}$

1.Universidade de São Paulo, São Paulo (SP), Brazil.

*Corresponding author: heitor.furlan.giordano@gmail.com

\section{BACKGROUND}

Cryoglobulinemic vasculitis (CryoVas) occurs due to several etiologies and evaluation for infections, autoimmune diseases and lymphoproliferative diseases is fundamental. Type 1 monoclonal CryoVas is characterized by high serum cryoglobulin levels, cutaneous involvement and lower frequency of glomerulonephritis than expected. Compared to monoclonal gammopathy of unknown significance (MGUS), type 1 CryoVas related to hematologic malignancy tended to be associated with a poorer prognosis.

\section{CASE REPORT}

A 32-year-old woman was admitted in our service to investigate a type 1 CryoVas. Two years before she began with cold urticaria diagnosis, leg pain, edema and a purpuric rash in lower extremities. Evaluation resulted in high levels of cryoglobulins and subnephrotic proteinuria. Skin biopsy showed leukocytoclastic vasculitis. Hepatitis serology and autoantibodies was negative. IgG/Kappa monoclonal gammopathy was identified, with peak $M 1.09 \mathrm{~g} / \mathrm{dL}$, free light chain ratio 0.68 , without calcium elevation, renal dysfunction, anemia, bone (CRAB) disease criteria. Due to suspected vasculitis with renal manifestation, she received metilprednisolona $1 \mathrm{~g} /$ day (3 days) and cyclophosphamide. Maintenance with azathioprine and prednisone $1 \mathrm{mg} / \mathrm{kg} / \mathrm{day}$ was started. At this moment, she was referred to our service and in the initial consultation she had anasarca, nephrotic proteinuria, dysmorphic hematuria with normal renal function. A new scheme of pulse therapy was performed and she received four cycles of cyclophosphamide followed by rituximab. Nonetheless, anasarca and proteinuria got worse and kidney dysfunction developed. Hospitalization was requested. Patient had $10 \mathrm{~kg}$ weight gain and edema of lower limbs. Diuretic therapy and extended investigation were started to evaluate amyloidosis and lymphoproliferative diseases. Renal biopsy demonstrated membranoproliferative glomerulonephritis with monoclonal lgG/Kappa deposits. Bone marrow biopsy found 10\% plasmocytes mainly Kappa; however, laboratory evaluation did not confirm end-organ damage attributable to myeloma (CRAB). Hematology assessment agreed with diagnosis of monoclonal gammopathy of renal significance (MGRS) and patient was referred to chemotherapy directed to plasma cell dyscrasia.

\section{CONCLUSION}

In patients with CryoVas, the investigation of infectious, autoimmune and lymphoproliferative diseases should identify the etiology and direct the correct treatment. In the case of type 1 , it is caused by lymphoproliferative disorders like multiple myeloma or MGRS. Thus, bone marrow and renal biopsy are essentials in monoclonal gammopathies with nephrotic proteinuria and renal damage. Once identified, those plasmacytic dyscrasias turn the focus of treatment in a case of type 1 CryoVas. 